\title{
Mapping the availability and accessibility of healthy food in rural and urban New Zealand - Te Wai o Rona: Diabetes Prevention Strategy
}

\author{
Jing Wang ${ }^{1,2}$, Margaret Williams ${ }^{3}$, Elaine Rush ${ }^{4}$, Nic Crook ${ }^{5}$, Nita G Forouhi ${ }^{1}$ and \\ David Simmons ${ }^{6, *}$ \\ ${ }^{1}$ Medical Research Council Epidemiology Unit, Institute of Metabolic Science, Cambridge, UK: ${ }^{2}$ Key Laboratory \\ of Nutrition and Metabolism, Institute for Nutritional Sciences, Shanghai Institutes for Biological Sciences, \\ Chinese Academy of Sciences, Shanghai, People's Republic of China: ${ }^{3}$ Te Roopu a Iwi o Te Arawa Charitable \\ Trust, Rotorua, New Zealand: ${ }^{4}$ Auckland University of Technology, Auckland, New Zealand: ${ }^{5}$ Lakes District

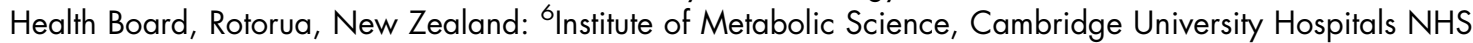 \\ Foundation Trust, Cambridge CB2 2QQ, UK
}

Submitted 22 September 2008: Accepted 21 August 2009: First published online 28 September 2009

\begin{abstract}
Objective: Uptake of advice for lifestyle change for obesity and diabetes prevention requires access to affordable 'healthy' foods (high in fibre/low in sugar and fat). The present study aimed to examine the availability and accessibility of 'healthy' foods in rural and urban New Zealand.

Design: We identified and visited ('mapped') 1230 food outlets (473 urban, 757 rural) across the Waikato/Lakes areas (162 census areas within twelve regions) in New Zealand, where the Te Wai O Rona: Diabetes Prevention Strategy was underway. At each site, we assessed the availability of 'healthy' foods (e.g. wholemeal bread) and compared their cost with those of comparable 'regular' foods (e.g. white bread).

Results: Healthy foods were generally more available in urban than rural areas. In both urban and rural areas, 'healthy' foods were more expensive than 'regular' foods after adjusting for the population and income level of each area. For instance, there was an increasing price difference across bread, meat, poultry, with the highest difference for sugar substitutes. The weekly family cost of a 'healthy' food basket (without sugar) was $29 \cdot 1 \%$ more expensive than the 'regular' basket ( $\$ N Z 176 \cdot 72 v$. $\$ N Z$ 136.84). The difference between the 'healthy' and 'regular' basket was greater in urban $(\$ N Z$ 49·18) than rural areas $(\$ N Z 36 \cdot 27)$ in adjusted analysis.

Conclusions: 'Healthy' foods were more expensive than 'regular' choices in both urban and rural areas. Although urban areas had higher availability of 'healthy' foods, the cost of changing to a healthy diet in urban areas was also greater. Improvement in the food environment is needed to support people in adopting healthy food choices.
\end{abstract}

Keywords
Food environment
Availability
Accessibility
It is estimated that nutrition-related risk factors accounted for $70 \%$ of stroke and heart disease mortality and more than $80 \%$ of diabetes in 1997 in New Zealand ${ }^{(1)}$. However, nutrition recommendations are often not met. For instance, in the 1990s, fat intake contributed about $35 \%$ of energy in the diet of New Zealanders, with saturated fat comprising $15 \%$ of total energy intake; while daily intake of dietary fibre was lower than the recommended $25-30 \mathrm{~g} / \mathrm{d}$, at $23 \mathrm{~g} / \mathrm{d}$ in men and $18 \mathrm{~g} / \mathrm{d}$ in women ${ }^{(2)}$.

Although both intervention trials and population studies have demonstrated that type 2 diabetes is preventable by adopting a healthy lifestyle ${ }^{(3)}$, lifestyle change requires a 'healthy' food environment since food choices are driven by taste, cost and convenience, rather than health and variety ${ }^{(4)}$. In spite of the current food-based dietary guidelines ${ }^{(5)}$ to eat foods low in fat, saturated fat, salt and sugar, unhealthy choices are often made. Almost one-half of the adult New Zealand population (47\%) was happy with their fat intake and $32 \%$ felt it would be hard to eat less high-fat (energy-dense) foods because they taste 'good' ${ }^{\text {(2) }}$. Categorising specific foods as healthy or unhealthy is fraught with difficulties and may create some confusion. A more practical way may be to rank foods within a food group as less healthy or more healthy, based on total energy, sugar, saturated fat, protein, fibre and fruit and vegetable content. Cost is another issue in 
New Zealand, with 30-34\% of New Zealanders citing it as the major barrier associated with eating more fruit and vegetables $^{(6)}$. Drewnowski et al. reported an inverse association between dietary energy density $(\mathrm{MJ} / \mathrm{kg})$ and energy cost $(\$ / M J)^{(7)}$; thus energy-dense foods composed of refined grains, added sugars or fats may represent the best energy-to-cost option for low-income consumers, among whom the highest rates of obesity are observed. Limited availability of healthy foods in low-income neighbourhoods ${ }^{(8)}$ might also cause food security problems in addition to lack of money ${ }^{(9)}$.

Several observational studies conducted in European countries (e.g. the UK, Denmark and France) have shown that healthier diets cost more than less healthy options ${ }^{(10-13)}$. Market-basket surveys have also revealed the additional cost of healthier options. Jetter and Cassady found an annual premium of \$US 936 on the 'healthier basket' compared with the Thrifty Food Plan shopping basket ${ }^{(8)}$. However, results from intervention studies are inconsistent, as documented by McAllister et al. ${ }^{(14)}$, which suggests that it is possible to select a healthy diet without extra financial burden. Both Raynor et $a l^{(15)}$ and Mitchell et al. ${ }^{(16)}$ reported that healthy diets do not represent an increased financial burden to the consumer and may actually cost less.

There is limited evidence from New Zealand, with only two identified studies regarding cost of foods as a barrier to adopting healthy eating habits. Wilson and Mansoor reported $49 \%$ and $22 \%$ higher cost of the low-saturatedfat equivalent of nine selected foods in two large supermarkets, respectively ${ }^{(17)}$. Ni Mhurchu and Ogra found a moderate increase in cost (\$NZ 334 annual household cost) for a 'healthy' basket compared with a 'regular' food basket $^{(18)}$. However, these studies were conducted in one or two supermarkets in one city, hence were not generalisable more widely, and were unable to detect any urban-rural difference. The aim of the present study was to compare the price of 'healthy' $v$. 'regular' alternatives in one urban area (the largest town, population 120000 ) and surrounding rural areas in New Zealand as part of the Te Wai o Rona: Diabetes Prevention Strategy ${ }^{(19)}$, as a prelude to enhancing healthy food access. Healthier choices were defined according to the New Zealand food-based dietary guidelines as less energy-dense, lower in fat, salt and sugar and higher in fibre ${ }^{(5)}$ than the regular alternatives.

\section{Materials and methods}

We 'mapped' the availability of 'healthy' foods and compared their prices with those of comparable 'regular' choices between June and August 2005 across the Waikato/Lakes areas involved in the Te Wai o Rona: Diabetes Prevention Strategy. A list of outlets was compiled from the Waikato and Lakes District Councils' databases, the New Zealand Business Directory database obtained through Google search engines, and local knowledge obtained from consultation with local Maori community health workers. The list contained all registered venues where food was sold including supermarkets, dairies, bakeries, service stations, restaurants and takeaways. We chose a non-experiment survey design, and visited all premises. After excluding venues subsequently closed, information was available from 1230 of 1234 outlets (473 'urban', i.e. in Hamilton; 757 'rural', i.e. out of Hamilton) covering 162 areas of twelve regions (Fig. 1).

Food prices, and the associated weight, were collected using standard questionnaires for each venue by local Maori community health workers and researchers. For supermarkets, large dairies (small grocery shops) or other venues where people did grocery shopping, the availability of fifteen 'healthy' food items was recorded. In addition, eight food categories, i.e. milk, bread, drinks, sugar, spreads, chicken, beef/pork and snacks, were selected for price comparison between 'regular' (full-fat milk, white bread, sugar-sweetened drinks, sugar, full-fat spreads, chicken with skin, regular beef/pork and unhealthy snacks) and 'healthy' alternatives (skimmed milk, wholemeal bread, diet drinks, sugar substitutes, low-fat spreads, chicken without skin, lean beef/pork and healthy snacks), and the prices of these foods were recorded. For restaurants and takeaways where people get ready-to-eat food, eighteen food categories were selected and the availability of 'healthy' choices was recorded.

Only the outlets that had both 'regular' and 'healthy' alternatives were included in the analysis of price comparison. For sweeteners, the regular form is solid, and substitute sweeteners can be both solid and liquid. Because it is difficult to compare between different forms, only solid forms or liquid alternatives with known weight were included in the analysis. While sweeteners may not be considered a healthy food by some, they are an alternative to sugar to help reduce energy intake and, in this way, may be useful in some individuals in the prevention of diabetes. They were therefore categorised as a healthier alternative to sugar.

Information on population size, income, ethnicity, smoking habit and socio-economic status (employment, vehicle and house ownership, education level) for each area and region was obtained from the 2006 Census of Population and Dwellings in New Zealand ${ }^{(20)}$. Ethnicity was assigned by self-identity in the census. Census areas in the major town in the area (Hamilton) were classed as urban, with all other areas classed as rural.

The estimated food and 'basket' costs were calculated using the average price per unit weight of food in each category. The weekly estimated amounts of food required for a household comprising one adult male, one adult female, one adolescent boy and one adolescent girl were based on the New Zealand Food and Nutrition Guidelines to meet the nutritional needs of most healthy people ${ }^{(21)}$.

Low-risk ethical approval for this research was obtained from the Massey University Human Ethics Committee and 


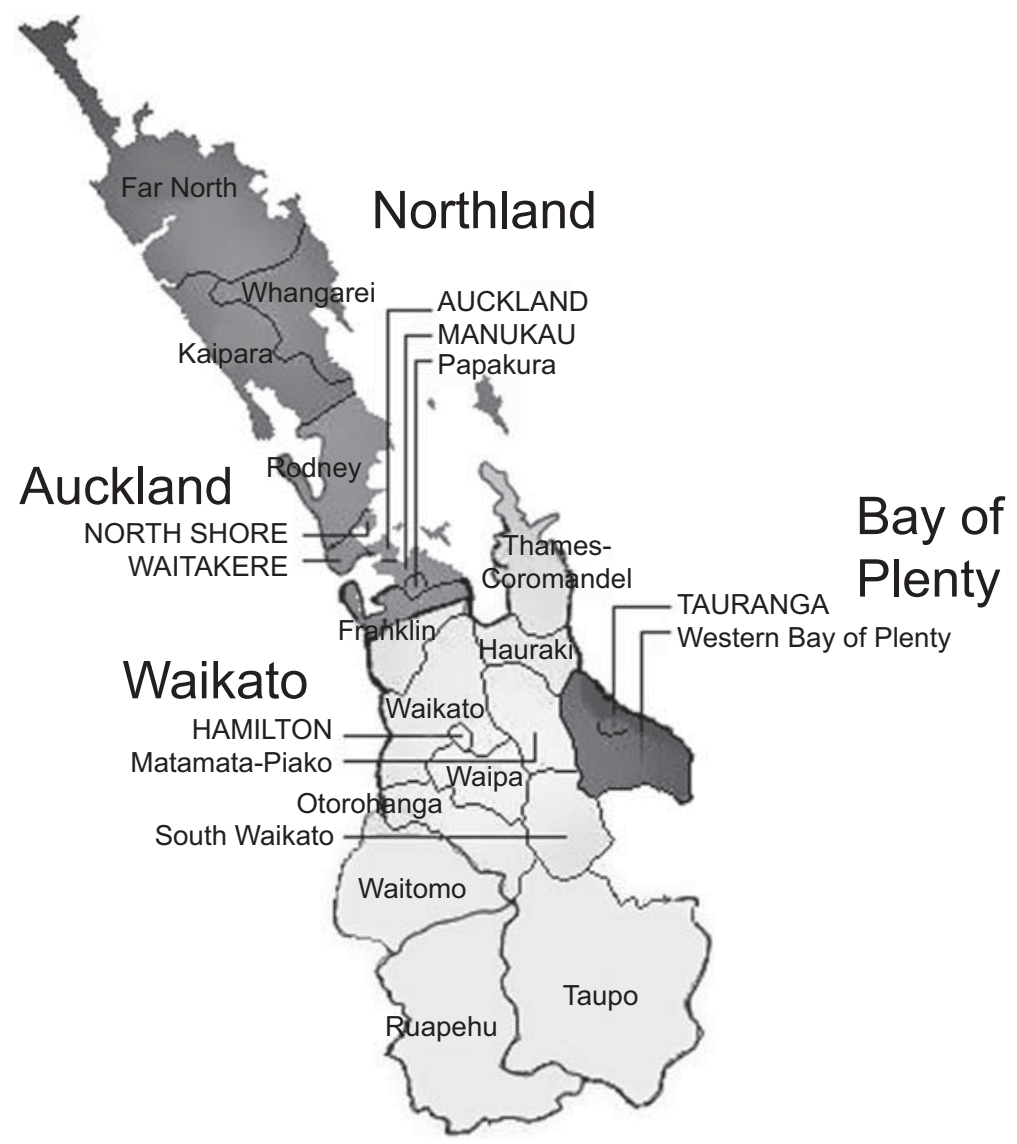

Fig. 1 Map of Waikato/Lakes areas with Hamilton as urban area and surrounding areas as rural areas. The study zone is shown by the lighter shaded areas

from the Lakes District Health Board Research and Ethics Committee.

\section{Statistical analyses}

Results are expressed as means and standard deviations for continuous variables and as frequencies and percentages for categorical variables. Differences in food prices between urban and rural areas were compared using paired $t$ tests for those outlets with the option of both 'regular' and 'healthy' foods and as a multivariable regression model (general linear model) adjusting for population size, ethnicity (proportion of European residents), income (median income) and education level (proportion of people without qualification). Food prices between 'regular' and 'healthy' choices were compared in the form of both single food items and food 'baskets' with the estimated weekly amount for a four-person family. The difference between the 'regular' and 'healthy' food price was expressed as ('healthy' food price - 'regular' food price)/'regular' food price $\times 100 \%$. The estimated food basket costs were compared using the percentage of difference relative to the cost of the 'regular' basket. Differences in socio-economic status between urban and rural area were tested using Goodman and Kruskal's gamma. All statistics were performed using the STATA statistical software package version $9 \cdot 2$ (StataCorp, College Station, TX, USA).
For background, Table 1 reports the 2006 census results showing that the urban population had a smaller proportion of Europeans and larger proportions of Pacific Islanders and Asian people, and had greater prevalence of unemployment, deprivation (i.e. without motor vehicles or house ownership) and low income rates than rural areas. The proportion of smokers and people with no qualifications was higher in rural areas. Urban areas had a larger population size, but slightly lower median income.

\section{Results}

\section{Availability of 'bealtby' food choices}

The availability of 'healthy' food choices in both urban and rural areas is shown in Table 2 . The availability of most categories in grocery outlets was above $50 \%$ with the exception of baked potatoes without butter (13.3\% in urban and $18.9 \%$ in rural areas), lower-calorie ice cream (40.4\% in urban and $46.3 \%$ in rural areas), lean cuts of meats in urban areas $(33.7 \%)$ and low-calorie yoghurt in rural areas (48.4\%). The availability of wholemeal bread, sugar-free drinks and fresh/canned fruit was higher in urban areas, while the availability of salads and lean cuts of meats was higher in rural areas. The availability of all the other items was not significantly different between urban and rural areas. 
Table 1 Baseline social-economic status from the 2006 Census of Population and Dwellings in New Zealand ${ }^{(20)}$ for the Waikato/Lake areas

\begin{tabular}{|c|c|c|c|c|c|}
\hline & \multicolumn{2}{|c|}{ Urban* } & \multicolumn{2}{|c|}{ Ruralt } & \multirow[b]{2}{*}{$P$ value } \\
\hline & $n$ & $\%$ & $n$ & $\%$ & \\
\hline \multicolumn{6}{|l|}{ Ethnicity } \\
\hline European & 195375 & $55 \cdot 12$ & 138396 & $65 \cdot 02$ & \multirow[t]{4}{*}{$<0.001$} \\
\hline Maori & 75039 & $21 \cdot 17$ & 43932 & $20 \cdot 64$ & \\
\hline Pacific & 20190 & $5 \cdot 70$ & 3738 & $1 \cdot 76$ & \\
\hline Asian & 28233 & $7 \cdot 97$ & 3984 & $1 \cdot 87$ & \\
\hline \multicolumn{6}{|l|}{ Employment } \\
\hline Full-time & 118566 & $46 \cdot 91$ & 72582 & $47 \cdot 32$ & \multirow[t]{3}{*}{$<0.001$} \\
\hline Part-time & 34185 & $13 \cdot 52$ & 22674 & $14 \cdot 78$ & \\
\hline Unemployed & 12534 & 4.96 & 4632 & 3.02 & \\
\hline \multicolumn{6}{|l|}{ Vehicle } \\
\hline None & 9951 & $8 \cdot 61$ & 4740 & $6 \cdot 43$ & \multirow[t]{4}{*}{$<0.001$} \\
\hline One & 44280 & $38 \cdot 29$ & 26640 & $36 \cdot 13$ & \\
\hline Two & 39210 & 33.91 & 27573 & $37 \cdot 40$ & \\
\hline Three or more & 16056 & $13 \cdot 89$ & 11577 & $15 \cdot 70$ & \\
\hline \multicolumn{6}{|l|}{ Tenure } \\
\hline Own or partly own & 108777 & $43 \cdot 03$ & 81618 & $53 \cdot 22$ & \multirow[t]{2}{*}{$<0.001$} \\
\hline Not own & 126147 & $49 \cdot 90$ & 61974 & $40 \cdot 41$ & \\
\hline \multicolumn{6}{|l|}{ Income (\$NZ) } \\
\hline$\leq 5000$ & 31545 & $12 \cdot 48$ & 15855 & $10 \cdot 34$ & \multirow[t]{6}{*}{$<0.001$} \\
\hline $5001-10000$ & 20394 & 8.07 & 11124 & $7 \cdot 25$ & \\
\hline $10001-20000$ & 49758 & $19 \cdot 68$ & 33573 & $21 \cdot 89$ & \\
\hline $20001-30000$ & 34902 & $13 \cdot 81$ & 22803 & $14 \cdot 87$ & \\
\hline $30001-50000$ & 53292 & $21 \cdot 08$ & 31503 & $20 \cdot 54$ & \\
\hline$>50000$ & 34683 & $13 \cdot 72$ & 21813 & $14 \cdot 22$ & \\
\hline \multicolumn{6}{|l|}{ Smoking } \\
\hline Current & 54189 & $21 \cdot 44$ & 33798 & $22 \cdot 03$ & \multirow[t]{3}{*}{$<0.001$} \\
\hline Former & 45384 & $17 \cdot 96$ & 33324 & $21 \cdot 72$ & \\
\hline Never & 129738 & $51 \cdot 33$ & 72522 & $47 \cdot 28$ & \\
\hline \multicolumn{6}{|l|}{ Education } \\
\hline No qualification & 59016 & $26 \cdot 29$ & 45003 & $33 \cdot 21$ & \multirow[t]{3}{*}{$<0.001$} \\
\hline Secondary school qualification only & 110496 & $49 \cdot 22$ & 66216 & $48 \cdot 86$ & \\
\hline Higher qualification & 54990 & $24 \cdot 49$ & 24297 & $17 \cdot 93$ & \\
\hline
\end{tabular}

*Urban population = 328299; median income = \$NZ 23305.

tRural population = 199500; median income $=\$ N Z 23619$.

Table 2 Availability of 'healthy' food in food outlets (excluding takeaways, cafés and restaurants) in urban and rural areas - Te Wai o Rona: Diabetes Prevention Strategy, June-August 2005

\begin{tabular}{|c|c|c|c|c|c|c|}
\hline \multirow[b]{2}{*}{ Availability } & \multicolumn{2}{|c|}{ Urban (n 129) } & \multicolumn{2}{|c|}{ Rural (n 236) } & \multirow[b]{2}{*}{ Difference* $(\%)^{\circ}$} & \multirow[b]{2}{*}{$P$ value } \\
\hline & $n$ & $\%$ & $n$ & $\%$ & & \\
\hline Wholemeal bread & 94 & $82 \cdot 5$ & 149 & $66 \cdot 2$ & $16 \cdot 2$ & 0.002 \\
\hline High-fibre cereals & 104 & $88 \cdot 1$ & 201 & $81 \cdot 1$ & $7 \cdot 1$ & 0.089 \\
\hline Wholemeal pasta & 60 & $51 \cdot 7$ & 138 & $57 \cdot 5$ & $-5 \cdot 8$ & 0.304 \\
\hline Sugar-free drinks & 105 & $88 \cdot 2$ & 180 & $78 \cdot 6$ & $9 \cdot 6$ & 0.027 \\
\hline Water & 107 & $89 \cdot 9$ & 235 & $93 \cdot 6$ & $-3 \cdot 7$ & $0 \cdot 208$ \\
\hline Fresh/canned fruit & 103 & $85 \cdot 1$ & 168 & $68 \cdot 3$ & $16 \cdot 8$ & 0.001 \\
\hline Salads & 33 & $44 \cdot 0$ & 124 & $57 \cdot 7$ & $-13 \cdot 7$ & 0.041 \\
\hline Baked potato without butter & 8 & $13 \cdot 3$ & 34 & $18 \cdot 9$ & $-5 \cdot 6$ & $0 \cdot 327$ \\
\hline Fresh/canned vegetables & 97 & $81 \cdot 5$ & 204 & $81 \cdot 3$ & 0.2 & 0.956 \\
\hline Lean cuts of meats & 29 & $33 \cdot 7$ & 121 & $52 \cdot 6$ & $-18 \cdot 9$ & 0.003 \\
\hline Canned fish in water & 68 & $61 \cdot 8$ & 169 & $71 \cdot 9$ & $-10 \cdot 1$ & 0.059 \\
\hline Low-calorie yoghurt & 62 & $57 \cdot 9$ & 108 & $48 \cdot 4$ & $9 \cdot 5$ & $0 \cdot 106$ \\
\hline Low-fat milk & 110 & $90 \cdot 9$ & 233 & $92 \cdot 5$ & $-1 \cdot 6$ & $0 \cdot 606$ \\
\hline Low-calorie ice cream & 44 & $40 \cdot 4$ & 111 & $46 \cdot 3$ & $-5 \cdot 9$ & 0.305 \\
\hline Low-fat spreads & 89 & $75 \cdot 4$ & 191 & $77 \cdot 0$ & $-1 \cdot 6$ & 0.737 \\
\hline
\end{tabular}

*Difference was calculated as urban availability minus rural availability.

\section{Food price in urban and rural areas}

There was no significant difference in the price of 'regular' foods between urban and rural areas with the exception of white bread, which was more expensive in rural areas (\$NZ 2.99 v. $\$ \mathrm{NZ} 3.34$ per $\mathrm{kg}, P=0.003)$.
'Healthy' food choices such as skimmed milk ( $\$ \mathrm{NZ} 1 \cdot 90 \mathrm{v}$. $\$ N Z 1.83$ per litre, $P=0.023)$ and healthy snacks (\$NZ $23 \cdot 13$ vs. $\$ N Z 19 \cdot 61$ per $\mathrm{kg}, P=0 \cdot 014$ ) were more expensive in rural areas, while lean cuts of meats ( $\$ \mathrm{NZ}$ $19.79 v$. $\$ \mathrm{NZ} 15 \cdot 22$ per kg, $P=0.023$ ) were less expensive 
Table 3 Comparison of food prices $(\$ N Z / k g)$ between 'regular' and 'healthy' food alternatives - Te Wai o Rona: Diabetes Prevention Strategy, June-August 2005

\begin{tabular}{|c|c|c|c|c|c|c|c|c|c|c|c|c|c|}
\hline & \multirow[b]{3}{*}{$n$} & \multicolumn{6}{|c|}{ Unadjusted model } & \multicolumn{6}{|c|}{ Adjusted model ${ }^{*}$} \\
\hline & & \multicolumn{2}{|c|}{ Regular } & \multicolumn{2}{|c|}{ Healthy } & \multirow[b]{2}{*}{$P$ value } & \multirow[b]{2}{*}{ Differencet (\%) } & \multicolumn{2}{|c|}{ Regular } & \multicolumn{2}{|c|}{ Healthy } & \multirow[b]{2}{*}{$P$ value } & \multirow[b]{2}{*}{ Differencet (\%) } \\
\hline & & Mean & SD & Mean & SD & & & Mean & SD & Mean & SD & & \\
\hline Bread & 509 & $3 \cdot 21$ & 0.06 & 3.54 & 0.05 & $<0.001$ & $10 \cdot 3$ & 3.22 & 0.05 & 3.54 & 0.05 & $<0.001$ & $9 \cdot 9$ \\
\hline Chicken & 90 & $7 \cdot 48$ & 0.35 & $13 \cdot 25$ & 0.59 & $<0.001$ & $77 \cdot 1$ & $7 \cdot 42$ & 0.50 & $13 \cdot 35$ & 0.50 & $<0.001$ & $80 \cdot 6$ \\
\hline Meat & 186 & 12.94 & 0.43 & $15 \cdot 91$ & 0.50 & $<0.001$ & 23.0 & 13.05 & 0.47 & 15.96 & 0.47 & $<0.001$ & $22 \cdot 3$ \\
\hline Drinks & 750 & 2.93 & 0.07 & 3.02 & 0.06 & 0.3085 & $3 \cdot 1$ & $2 \cdot 96$ & 0.06 & 3.05 & 0.06 & 0.355 & $3 \cdot 0$ \\
\hline Milk & 518 & 1.90 & 0.02 & $1 \cdot 87$ & 0.01 & $0 \cdot 1123$ & -1.6 & 1.91 & 0.02 & $1 \cdot 88$ & 0.02 & $0 \cdot 269$ & -1.6 \\
\hline Snacks & 687 & 25.08 & $4 \cdot 21$ & $21 \cdot 56$ & $0 \cdot 71$ & 0.4106 & $-14 \cdot 0$ & $25 \cdot 16$ & 3.04 & $21 \cdot 68$ & 3.04 & 0.419 & $-13 \cdot 8$ \\
\hline Spreads & 360 & $6 \cdot 59$ & $0 \cdot 13$ & 8.49 & 0.22 & $<0.001$ & $28 \cdot 8$ & $6 \cdot 63$ & $0 \cdot 18$ & 8.53 & $0 \cdot 18$ & $<0.001$ & $28 \cdot 7$ \\
\hline Sugar & 85 & $2 \cdot 07$ & $0 \cdot 14$ & $90 \cdot 54$ & $4 \cdot 48$ & $<0.001$ & 4273.9 & $2 \cdot 14$ & $3 \cdot 31$ & $89 \cdot 49$ & $3 \cdot 31$ & $<0.001$ & $4081 \cdot 8$ \\
\hline
\end{tabular}

*Adjusted for population size, ethnicity, income and education level from the 2006 Census of Population and Dwellings in New Zealand ${ }^{(20)}$ (see Materials and methods section).

tRepresents the percentage price difference between the 'healthy' option and 'regular' option, compared with the 'regular' food option (see Materials and methods section).

Table 4 Comparison of price (\$NZ) of 'regular' and 'healthy' food baskets* - Te Wai o Rona: Diabetes Prevention Strategy, June-August 2005

\begin{tabular}{|c|c|c|c|c|c|c|}
\hline & \multicolumn{6}{|c|}{ Family weekly cost } \\
\hline & \multicolumn{3}{|c|}{ Unadjusted model } & \multicolumn{3}{|c|}{ Adjusted modelt } \\
\hline & All & Urban & Rural & All & Urban & Rural \\
\hline \multicolumn{7}{|l|}{ 'Regular' basket } \\
\hline Bread, white & $20 \cdot 87$ & $19 \cdot 44$ & $21 \cdot 71$ & $20 \cdot 93$ & $20 \cdot 02$ & $21 \cdot 52$ \\
\hline Chicken, with skin & $30 \cdot 67$ & $28 \cdot 78$ & $32 \cdot 06$ & $30 \cdot 42$ & $28 \cdot 25$ & $32 \cdot 19$ \\
\hline Meat, beef/pork & $53 \cdot 05$ & $51 \cdot 25$ & $53 \cdot 71$ & $53 \cdot 51$ & $49 \cdot 12$ & $55 \cdot 19$ \\
\hline Drinks, sugary & $1 \cdot 17$ & $1 \cdot 20$ & $1 \cdot 16$ & $1 \cdot 18$ & $1 \cdot 22$ & $1 \cdot 17$ \\
\hline Milk, regular & $24 \cdot 70$ & $24 \cdot 44$ & 24.96 & $24 \cdot 83$ & $23 \cdot 79$ & $25 \cdot 35$ \\
\hline Spreads, regular & 5.93 & $6 \cdot 17$ & $5 \cdot 82$ & $5 \cdot 97$ & $5 \cdot 96$ & 5.97 \\
\hline Sugar, regular & $3 \cdot 21$ & $3 \cdot 47$ & 3.07 & $3 \cdot 32$ & 3.39 & $3 \cdot 29$ \\
\hline Total & $139 \cdot 60$ & $134 \cdot 76$ & $142 \cdot 49$ & $140 \cdot 16$ & $131 \cdot 75$ & $144 \cdot 66$ \\
\hline Total (without sugar) & $136 \cdot 39$ & $131 \cdot 29$ & $139 \cdot 42$ & $136 \cdot 84$ & $128 \cdot 35$ & $141 \cdot 38$ \\
\hline \multicolumn{7}{|l|}{ ‘Healthy’ basket } \\
\hline Bread, wholemeal & $23 \cdot 01$ & $22 \cdot 23$ & $23 \cdot 47$ & $23 \cdot 01$ & $23 \cdot 34$ & $22 \cdot 95$ \\
\hline Chicken, without skin & $54 \cdot 33$ & 53.96 & $54 \cdot 61$ & 54.94 & $51 \cdot 17$ & $57 \cdot 56$ \\
\hline Meat, lean beef/pork & $65 \cdot 23$ & $72 \cdot 94$ & $62 \cdot 40$ & $65 \cdot 44$ & $69 \cdot 91$ & $63 \cdot 76$ \\
\hline Drinks, water & $1 \cdot 21$ & $1 \cdot 27$ & $1 \cdot 18$ & $1 \cdot 22$ & $1 \cdot 30$ & $1 \cdot 18$ \\
\hline Milk, skimmed & $24 \cdot 31$ & $23 \cdot 79$ & $24 \cdot 70$ & $24 \cdot 44$ & $24 \cdot 05$ & 24.57 \\
\hline Spreads, low-fat & $7 \cdot 64$ & $7 \cdot 50$ & $7 \cdot 71$ & $7 \cdot 68$ & $7 \cdot 78$ & $7 \cdot 63$ \\
\hline Sugar, substitute & $140 \cdot 34$ & $151 \cdot 59$ & $134 \cdot 20$ & $138 \cdot 71$ & $164 \cdot 84$ & $122 \cdot 02$ \\
\hline Total & $316 \cdot 06$ & $333 \cdot 27$ & $308 \cdot 27$ & $315 \cdot 43$ & $342 \cdot 38$ & $299 \cdot 66$ \\
\hline Total (without sugar substitute) & $175 \cdot 73$ & $181 \cdot 68$ & $174 \cdot 07$ & $176 \cdot 72$ & $177 \cdot 53$ & $177 \cdot 65$ \\
\hline
\end{tabular}

*Basket cost was estimated as sum of (average price per unit weight $\times$ estimated weekly family consumption amount) (see Materials and methods section). tAdjusted for population size, ethnicity, income and education level.

in rural areas. There was no significant difference in the price of wholemeal bread, unskinned chicken, sugar-free drinks, low-fat spreads and sugar substitutes between urban and rural areas. After adjusting for socio-economic factors, these differences were attenuated and nonsignificant with the exception of sugar substitutes, which were still more expensive in urban areas ( $\$$ NZ 109.27v. \$NZ $76 \cdot 86$ per kg, $P=0 \cdot 029$ ).

\section{Price comparison of 'regular' and 'bealtby' \\ food choices}

A comparison of the prices of single food items between 'regular' foods and 'healthy' alternatives is presented in Table 3. The 'healthy' alternatives were generally more expensive than 'regular' foods with the exception of drinks, milk and snacks. The same pattern was observed in urban and rural areas respectively, thus only the pooled results are presented. Adjusting for socioeconomic factors did not materially change the results.

The family weekly costs of 'regular' and 'healthy' food baskets are shown in Table 4. Overall, the 'healthy' basket was $125 \%$ more expensive than the 'regular' basket ( $\$ \mathrm{NZ}$ $315 \cdot 43 v$. \$NZ 140.16) after adjusting for socio-economic factors, with $77 \cdot 3 \%$ of the difference contributed by sugar substitutes. The 'healthy' basket was $14 \cdot 3 \%$ more expensive in urban areas than in rural areas in the adjusted analysis (\$NZ 342.38 v. \$NZ 299.66), but the 'regular' basket was less expensive in urban areas (\$NZ 131.75 v. \$NZ 144.66). 
Therefore, the difference between 'regular' and 'healthy' baskets was larger in urban areas (\$NZ 210.63 v. \$NZ 155.00). Taking sweeteners out of the baskets attenuated the difference between 'healthy' and 'regular' baskets, but did not change the overall pattern. The 'healthy' basket without sugar substitutes was still 29.1\% more expensive than the 'regular' basket without sugar after adjusting for socio-economic factors ( $\$ \mathrm{NZ} 176 \cdot 72 v$. \$NZ 136・84). The difference between 'regular' and 'healthy' baskets without sugar or sugar substitutes was \$NZ 49.18 in urban areas and $\$ N Z 36 \cdot 27$ in rural areas.

\section{Discussion}

We found in New Zealand that 'healthy' food choices were more available in urban than rural areas, and that 'healthy' food choices were more expensive than 'regular' choices in both rural and urban areas, even after adjusting for socioeconomic factors. The estimated weekly family cost of a 'healthy' basket of food was $125 \%$ more expensive than a 'regular' basket. Although the prices of single food items were comparable between urban and rural areas, the difference in cost between the 'regular' and 'healthy' basket was larger in urban than in rural areas.

Our results add new evidence regarding food price as a barrier to adopting healthy diets and extend previous findings to a more representative collection of food venues including both urban and rural areas. Wilson and Mansoor compared the price of the highest-saturated-fat $v$. lowest-saturated-fat alternatives of nine ready-to-eat food items in two large supermarkets in Wellington in a pilot study, and found that foods with the highest saturated fat were cheaper than their low-saturated-fat equivalents ${ }^{(17)}$. However, the price difference between the two sampling supermarkets was substantial. Ni Mhurchu and Ogra also reported higher costs for a 'healthy' basket in the Supermarket Healthy Options Project using electronic sales data from Pak'N'Save supermarket chain shops in Wellington ${ }^{(18)}$. However, the difference between 'regular' and 'healthy' baskets was relatively small, with the 'healthy' basket being $7 \%$ more expensive (\$NZ 96.63 v. \$NZ 90.21). Therefore, we collected food prices in a survey method covering all of the supermarkets, dairies, service stations, restaurants, takeaways and bakeries in 162 areas within twelve regions, and also took into account the population, ethnicity, income and education level of each area using survey data from the 2006 Census of Population and Dwellings in New Zealand ${ }^{(20)}$. By including all of the retail food outlets in the area we were able to differentiate between urban and rural locations. While a further analysis of food availability by store type and location would be of interest, our study was not powered to detect differences at this level. Block and Kouba reported a similar limitation in their comparison of the availability and affordability of a market basket by store type in two communities in an urban area $^{(22)}$. They showed it was more difficult in the lowerincome community to obtain acceptable quality foods for an optimal diet than in the more affluent community.

The difference in the price of sweeteners found in our study was unexpected. In the main, highly processed foods such as white flour and sugar are cheaper than less processed probably due their market dominance and ability to be stored longer than the unprocessed alternatives. We expected that sweeteners could be more expensive in rural areas. Therefore the difference in price of the sweeteners was unexpected and may be an anomaly related to store type, brands stocked and stock rotation issues. Although a large proportion of the difference between 'regular' and 'healthy' baskets came mainly from sugar substitutes, excluding sweeteners from the analysis did not remove the difference. Therefore, it is still more expensive in urban areas to adopt healthy diets even without the effect of sugar substitutes. If higher food costs represent both a real and a perceived barrier to dietary change, especially for lowerincome families, then the ability to adopt healthier diets may have less to do with psychosocial factors, self-efficacy or readiness to change than with household economic resources and the food environment. Continuing to recommend costly diets to low-income families as a public health measure can only generate frustration and culpability among the poor and less well-educated ${ }^{(23)}$. This is particularly important among Maori and Pacific families who are over-represented in low-income groups.

\section{Limitations and strengths}

The limitations of our study merit consideration. Although the food outlets list contained all registered venues where food was sold, we may have missed non-registered outlets such as roadside stalls. The spatial pattern of the stores was not available in our study either; therefore we are not able to examine the impact of distance on food price. The food prices were collected at one time point, but the usual prices were used in the analysis rather than any special discount price. In order to compare the 'regular' and 'healthy' food choices, we did not include fruits, vegetables or fish, which do not have 'unhealthy' alternatives. However, adopting healthy diets should include changing from high-fat foods to low-fat alternatives, increasing the quality of fatty acids intake (PUFA $v$. SFA), and increasing the quantity and variety of fruit and vegetable intake. We are not able to include these diet differences in the 'healthy' $v$. 'regular' basket comparison.

Our study has several strengths. To the best of our knowledge, this is the first large-scale 'healthy' food survey in New Zealand. We chose a non-experiment survey design which covered all 1230 registered food outlets in 162 areas of twelve regions, and collected the prices of 'regular' and 'healthy' choices of eight food categories. Considering the potential difference in food supply because of scale effects and/or other socio-economic factors, we took into account 
the population size, ethnicity, income and education level of each area in the analysis. The difference in price per unit weight might not reflect the cost difference of real diets and small differences for single food items might accumulate to a larger extent because of large consumption amount in real diets, thus we also compared the family cost of a 'healthy' food basket with the 'regular' alternative calculated using the estimated family consumption of each food category that would meet nutrition requirements.

We conclude that 'healthy' food is widely available in both urban and rural areas, although it is more available in urban areas. 'Healthy' diets are more expensive than 'regular' diets, and more so in urban areas than rural areas. Improvement in the food environment is needed to facilitate the adoption of healthy food choices.

\section{Acknowledgements}

The study was supported by the Medical Research Council Epidemiology Unit and the Ellison Medical Foundation International Nutrition Foundation. The Te Wai O Rona: Diabetes Prevention Strategy Mapping Study was funded by the Health Research Council, the Waikato District Health Board, the Lakes District Health Board, the Ministry of Health and Waikato Local Diabetes Team. There are no conflicts of interest. D.S. designed the overall study and was involved in every stage of undertaking and writing up the study and analysing the data. J.W. analysed the data and wrote the first draft of the paper. M.W. contributed to design, undertook data collection and early analysis of data and contributed to the paper. E.R. and N.C. contributed to the study design and the paper. N.G.F. contributed to data analysis and the paper. D.S. thanks NIHR Cambridge Biomedical Research Centre for its support. All authors thank the local health services for their support.

\section{References}

1. Ministry of Health \& University of Auckland (2003) Nutrition and the Burden of Disease: New Zealand 1997-2011. Wellington: Ministry of Health; available at http://www.moh.govt.nz/moh.nsf/0/7B9C6DE0D0AC6483 CC256D7A000B58AB

2. Ministry of Health (1999) NZ Food: NZ People. Key Results of the 1997 National Nutrition Survey. Wellington: Ministry of Health.

3. Parillo M \& Riccardi G (2004) Diet composition and the risk of type 2 diabetes: epidemiological and clinical evidence. Br J Nutr 92, 7-19.

4. Drewnowski A \& Darmon N (2005) The economics of obesity: dietary energy density and energy cost. Am J Clin Nutr 82, 1 Suppl., 265S-273S.

5. Ministry of Health (2003) Food and Nutrition Guidelines for Healthy Adults: A Background Paper. Wellington: Ministry of Health.
6. Sullivan C, Oakden J, Young J, Lau M, Lawson R (2008) Pulp Fiction - The Facts Harvested. A study of New Zealanders' physical activity and nutrition. Preliminary Report. http://www.cancernz.org.nz/Uploads/Pulp_Fiction_ Nutrition_Analysis_Report_Final.pdf (accessed June 2009).

7. Drewnowski A, Darmon N \& Briend A (2004) Replacing fats and sweets with vegetables and fruits - a question of cost. Am J Public Health 94, 1555-1559.

8. Jetter KM \& Cassady DL (2006) The availability and cost of healthier food alternatives. Am J Prev Med 30, 38-44.

9. Rush E, Puniani N, Snowling N \& Paterson J (2007) Food security, selection, and healthy eating in a Pacific Community in Auckland New Zealand. Asia Pac J Clin Nutr 16, 448-454.

10. Andrieu E, Darmon N \& Drewnowski A (2006) Low-cost diets: more energy, fewer nutrients. Eur J Clin Nutr 60, 434-436.

11. Cade J, Upmeier H, Calvert C \& Greenwood D (1999) Costs of a healthy diet: analysis from the UK Women's Cohort Study. Public Health Nutr 2, 505-512.

12. Darmon N, Briend A \& Drewnowski A (2004) Energy-dense diets are associated with lower diet costs: a community study of French adults. Public Health Nutr 7, 21-27.

13. Stender S, Skovby F, Haraldsdottir J, Andresen GR, Michaelsen KF, Nielsen BS \& Ygil KH (1993) Cholesterollowering diets may increase the food costs for Danish children. A cross-sectional study of food costs for Danish children with and without familial hypercholesterolaemia. Eur J Clin Nutr 47, 776-786.

14. McAllister M, Baghurst KI \& Record S (1994) Financial costs of healthful eating: a comparison of three different approaches. J Nutr Educ 26, 131-139.

15. Raynor HA, Kilanowski CK, Esterlis I \& Epstein LH (2002) A cost-analysis of adopting a healthful diet in a familybased obesity treatment program. J Am Diet Assoc 102, 645-656.

16. Mitchell DC, Shannon BM, Mckenzie J, Smiciklas-Wright H, Miller BM \& Tershakovec AM (2000) Lower fat diets for children did not increase food costs. J Nutr Educ 32, 100-103.

17. Wilson N \& Mansoor O (2005) Food pricing favours saturated fat consumption: supermarket data. $N Z \mathrm{Med} J$ 118, U1338.

18. Ni Mhurchu C \& Ogra S (2007) The price of healthy eating: cost and nutrient value of selected regular and healthier supermarket foods in New Zealand. $N Z$ Med J 120, U2388.

19. Simmons D, Rush E \& Crook N; on behalf of the Te Wai o Rona: Diabetes Prevention Strategy Team (2008) Development and piloting of a community health worker-based intervention for the prevention of diabetes among New Zealand Maori in Te Wai o Rona: Diabetes Prevention Strategy. Public Health Nutr 11, 1318-1325.

20. Statistics New Zealand (2007) 2006 Census of Population and Dwellings. http://www.stats.govt.nz/census/census-outputs/ meshblock/default.htm?tab=Download (accessed June 2009).

21. University of Otago (2004) Annual Food Cost Survey. Dunedin: Department of Human Nutrition, University of Otago; available at http://nutrition.otago.ac.nz/_data/ assets/file/0017/3671/InfoPackage.pdf

22. Block D \& Kouba J (2006) A comparison of the availability and affordability of a market basket in two communities in the Chicago area. Public Health Nutr 9, 837-845.

23. Drewnowski A (2004) Obesity and the food environment: dietary energy density and diet costs. Am J Prev Med 27, $154-162$. 